\title{
Use of Immunomodulators (Etanercept) in a Miniseries with Covid-19 Patients, to Decrease the Progress of Complications and Risks of Entry into Critical Care. Bibliography Review
}

\section{Adán Oliveros-Ceballos ${ }^{1 *}$, Janeth Gutiérrez-Segura ${ }^{2}$, Adrian Israel Ramirez-Mendoza $^{3}$ and Bryan Adan Oliveros-Galeana ${ }^{4}$}

${ }^{1}$ Director of Reproduction and Gyneacology of Acapulco Institute (IREGA), Guerrero, México

${ }^{2}$ Adscrit Pneumologist to Regional Hospital No 1 Vicente Guerrero of Acapulco Covid-19 Area, México

${ }^{3}$ Adscrit to Maternal Fetal Unit, México

${ }^{4}$ Adscrit to Biology of Reproduction Unit, México

*Corresponding Author: Adán Oliveros-Ceballos, Director of Reproduction and Gyneacology of Acapulco Institute (IREGA), Guerrero, México.

DOI: 10.31080/ASWH.2020.02.0128
Received: June 05, 2020

Published: July 30, 2020

(C) All rights are reserved by Adán

Oliveros-Ceballos., et al.

\begin{abstract}
Objective: This study aims to describe the clinical results of a miniseries of 6 patients who presented characteristic COVID-19 symptoms and PCR positive, who were administered Etanercept, to avoid Cytokine release syndrome with the purpose of decreasing admission to the critical care unit.

Design: This is a prospective, descriptive observational study.

Patients and Methods: 6 patients with (SARS-CoV-2) COVID-19 symptoms were evaluated for the administration of the immunomodulator Etanercept $50 \mathrm{mg}$. Two groups were aligned: A) Mild: with fever, cough, images compatible with pneumonia, and gastrointestinal symptoms; B) Moderate: with fever, cough, images compatible with pneumonia, gastrointestinal symptoms and respiratory distress considered as L phenotype.

Results: A total of 13 patients were identified with suspected infection of the virus (SARS-CoV-2) COVID-19, from which 6 patients accepted the administration of the immunomodulator Etanercept $50 \mathrm{mg}$ (subcutaneous) in a single dose and protocol follow-up. From these 6 patients: 4 patients had fever, cough, headache and risk factors such as pregnancy and obesity; and 2 patients also presented respiratory distress considered as L phenotype. All 6 evolved to improvement.

No patient was admitted to the critical intensive care unit and did not require invasive ventilatory support.

Conclusion: In this miniseries, the administration of the Etanercept immunomodulator in patients with (SARS-CoV-2) from mild to moderate stage, improved the clinical evolution and reduced the risk of admission to the intensive care unit. However, more patients and more controlled and randomized studies are necessary to recommend immunomodulators.

Keywords: COVID-19; Acute Respiratory Distress Syndrome (ARDS); Cytokine Storm; Inflammation; Anti-Inflammatory, Self-Induced Lung Damage (DPA); Tumor Necrosis Factor (TNF)
\end{abstract}

\section{Background}

At the end of December 2019, several patients with unexplained pneumonia appeared in Wuhan, China, a viral pneumonia that to this day is sweeping the world. The virus was identified as a new beta coronavirus and officially called coronavirus 2 of severe acute respiratory syndrome (SARS-CoV-2) [1,2]. Typical manifestations 
Use of Immunomodulators (Etanercept) in a Miniseries with Covid-19 Patients, to Decrease the Progress of Complications and Risks of Entry into Critical Care. Bibliography Review

consist of $80 \%$ flu-like symptoms such as fever, cough, fatigue, and dyspnea. However, in approximately $20 \%$ of patients, the infection progresses to severe interstitial pneumonia and can cause death. As of June 04 of 2020: 5,287,771 cases have been confirmed worldwide, and 379,941 deaths, according to the WHO, where, in Mexico, official reports shows 101,238 people confirmed, 157,354 negative, 44,869 suspects, 73,271 recovered, 16,829 active and 11,728 deaths; and in the state of Guerrero, there are 2,134 people confirmed, 1,784 negative, 1,321 suspects, 1,528 recovered, 235 active and 314 deaths by https://coronavirus.gob.mx/datos/\#DOView.

SARS-CoV-2, has quickly spread throughout the world, showing itself as its main characteristic of being able to spread and becoming a global health emergency.

For health systems, this has been an unforeseen health-economical contingency challenge. The schemes and protocols of containment -in the absence of the vaccine and not having a specific antiviral- place health systems in huge troubles. This is a great dilemma and with each day it's taking more lives in all countries, whether they have the right infrastructure or not, and the most punished today are the Latin American people.

Pneumonia appears to be the most frequent serious manifestation of infection, and approximately 6 to $10 \%$ of patients develop Acute Respiratory Distress Syndrome (ARDS), which requires continuous positive airway pressure therapy or mechanical ventilation.

The use of compassionate treatment schemes [3] is limited to follow the natural course of the disease, raising the chances for ventilatory support once patients arrive in the intensive care area as a last resource.

The concept of self-induced lung damage (APD) to the aberrant response of the host, is very well described by Jennifer $\mathrm{R}$ [4] and Adurrahman F [5]. They present the scenario of an emergency product of the infection-autoimmunity relationship, called cytokine release or cytokine storm figure 1 and 2, first described by Yuen [6] Which we can define as the exacerbated reaction to infections or biological therapy that is caused by the rapid recruitment of macrophages and neutrophils, which produce proinflammatory cytokines and alter the fragile balance between a controlled immune response and a reaction that damages the Guest.
Cytokine storms has also been reported from other coronavirus pandemics and other conditions that cause pulmonary hyperinflammation (Figure 1 and 2).

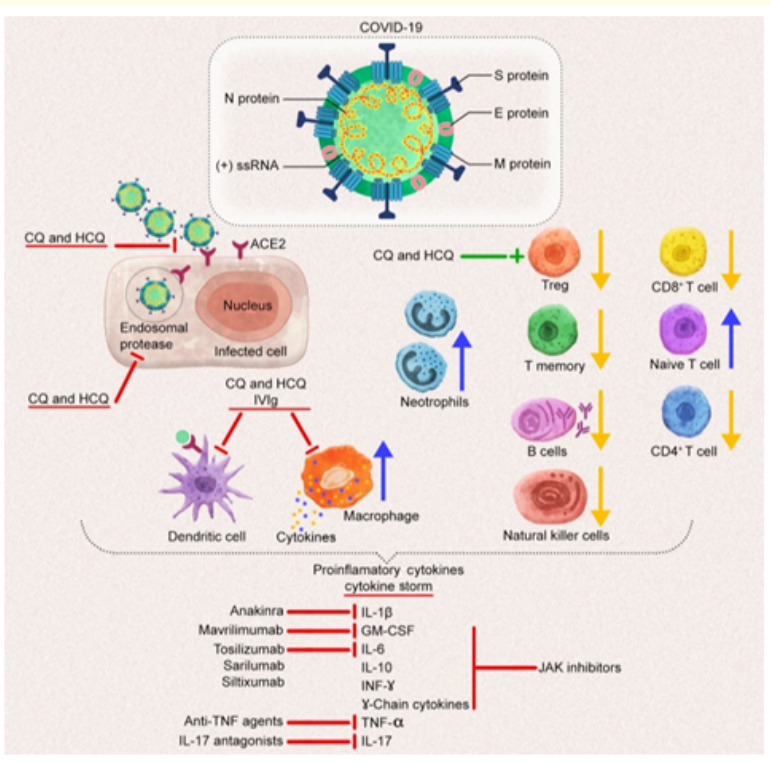

Figure 1: Adurrahman T. Turkish Journal of Medical Sciences, 2020.

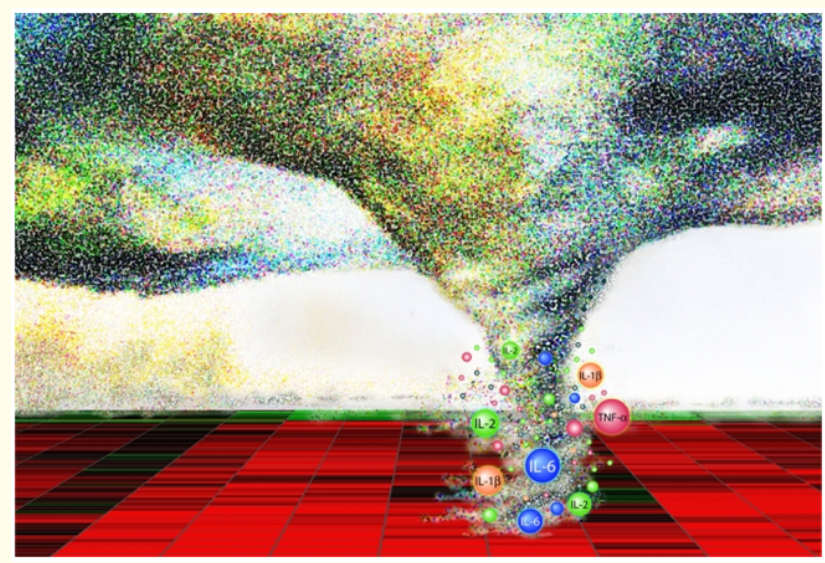

Figure 2 
Use of Immunomodulators (Etanercept) in a Miniseries with Covid-19 Patients, to Decrease the Progress of Complications and Risks of Entry into Critical Care. Bibliography Review

One of the alternatives against this entity is the use of immunosuppressants, also known as immunomodulators. According to a recent review of treatment alternatives by Favalli E [7], derived from the treatments used for rheumatoid arthritis, these are considered to have a modifying potential for the COVID-19 course, changing the effect initiated by the virus on the angiotensin-converting enzyme 2 (ACE2), identified on thr receptor's surface that triggers all the events that leads to lung damage, with sustained inflammation throughout the process.

Recently, Picchianti D [8] analyzed and reviewed the alternatives of immunomodulators with the possibility of obtaining aood response to severe interstitial pneumonia due to an uncontrolled host immune response, such as cytokine release syndrome (CRS). Under continuous monitoring (Table 1).

\begin{tabular}{|c|c|c|c|c|c|c|}
\hline & $\begin{array}{c}\text { Hydroxychloro- } \\
\text { quine/Chloro- } \\
\text { quine }\end{array}$ & $\begin{array}{c}\text { Tocilizumab/Sari- } \\
\text { lumab }\end{array}$ & Anakinra & Baricitinib & Adalimumab & Etanercept \\
\hline $\begin{array}{l}\text { Target } \\
\text { Population }\end{array}$ & $\begin{array}{l}\text { Mild with comor- } \\
\text { bidity } \\
\text { Moderate/severe }\end{array}$ & $\begin{array}{c}\text { Moderate/severe with or } \\
\text { without CRS }\end{array}$ & $\begin{array}{l}\text { Severe and } \\
\text { CRS }\end{array}$ & $\begin{array}{l}\text { Mild to severe, } \\
\text { with or without } \\
\text { CRS }\end{array}$ & Severe and CRS & $\begin{array}{l}\text { Leve toMild, } \\
\text { with or with- } \\
\text { out CRS }\end{array}$ \\
\hline $\begin{array}{l}\text { Main Safety } \\
\text { Exclusion } \\
\text { Criteria }\end{array}$ & $\begin{array}{l}\text { Consider drug-to- } \\
\text { drug interactions } \\
\text { (i.e., QT interval } \\
\text { prolongation) } \\
\text { Retinopathy } \\
\text { Severe renal dys- } \\
\quad \text { function }\end{array}$ & $\begin{array}{l}\text { Active TB and infections } \\
\text { other than COVID-19 } \\
\text { Bowel diverticulitis } \\
\text { Severe heart failure } \\
\text { Neut }<500 / \mathrm{mmc} \\
\text { Plt }<50,000 / \mathrm{mmc} \\
\text { Pregnancy }\end{array}$ & $\begin{array}{l}\text { Active TB and } \\
\text { infections } \\
\text { other than } \\
\text { COVID-19 } \\
\text { NYHA class } \\
\text { III/IV Severe } \\
\text { renal dysfunc- } \\
\text { tion } \\
\text { Pregnancy }\end{array}$ & $\begin{array}{l}\text { Active TB and } \\
\text { infections other } \\
\text { than COVID-19 } \\
\text { History of throm- } \\
\text { bophlebitis } \\
\text { Severe renal } \\
\text { dysfunction } \\
\text { Pregnancy }\end{array}$ & $\begin{array}{c}\text { Active TB and } \\
\text { infections other } \\
\text { than COVID-19 } \\
\text { NYHA class III/ } \\
\text { IV } \\
\text { Severe renal } \\
\text { dysfunction } \\
\text { Pregnancy }\end{array}$ & $\begin{array}{l}\text { No Active TB } \\
\text { and infections } \\
\text { other than } \\
\text { COVID-19 }\end{array}$ \\
\hline
\end{tabular}

Table 1: Anti-rheumatic immunological drugs currently tested in clinical trials of COVID-19 patients. Modif. Picchianti D- A Infection Int. J. Mol. Sci. 2020. 
Use of Immunomodulators (Etanercept) in a Miniseries with Covid-19 Patients, to Decrease the Progress of Complications and Risks of Entry into Critical Care. Bibliography Review

Etanercept [9] is an antagonist of tumor necrosis factor and was first used in human clinical studies in 1992 and was approved in January 2002 for the treatment of a group of autoimmune diseases such as severe pediatric psoriasis, psoriatic arthritis, rheumatoid arthritis, polyarticular juvenile idiopathic arthritis and ankylosing spondylitis.

The anti-inflammatory effects of etanercept are due to its ability to bind proinflammatory cytokine TNF, and its mechanisms of action is the ability to bind TNF, preventing it from interacting with cell surface receptors and rendering it biologically inactive. Etanercept can also modulate biological responses that are induced or regulated by TNF, including the expression of adhesive molecules responsible for leukocyte migration and serum levels of cytokines and metalloproteinase.
In 2001 Husselll [10] caused pulmonary viral disease in mice, improving the reduction of inflammatory infiltration with the use of tumor necrosis factor antagonists (etanercept), suggesting that the proven effects could be beneficial in the treatment of human viral diseases.

Yanik G [11] initiated the first treatments in three patients with idiopathic pneumonia syndrome (IPS), and diffuse, non-infectious acute lung injury secondary to hematopoietic stem cell transplantation where it is associated with respiratory failure and mortality rates above $50 \%$. Using etanercept in combination with corticosteroids demonstrates that it is safe and that give good results, and more authors have proposed them for this indication (Table 2). Adverse effects have also been reported, such as acute respiratory syndrome associated with the use of etanercept when used for a long time (over 2 years) and associated with corticosteroids.

\begin{tabular}{|l|c|c|c|c|c|}
\hline Year & Author & No. Cases & Indication & Other Treat. & Results \\
\hline 2001 & Hussell T & Ratones & Induced pneumonia & & Favorable results \\
\hline 2002 & Yanik, G & 3 & Idiopathic pneumonia. Sec. T & Corticosteroids & Favorable results \\
\hline 2004 & Tobinick. E & Recommendation & SARS & & Favorable results \\
\hline 2008 & Yanik, G & 15 & Idiopathic pneumonia. Sec. T & Corticosteroids & \\
\hline 2012 & Khaja, M & 1 & Respiratory distress syndrome & & Favorable results \\
\hline 2017 & Thompson. J & 23 & Idiopathic pneumonia. Sec. T & Corticosteroids & Favorable results \\
\hline 2020 & Marie D-P & 1 & COVID-19 & & Favorable results \\
\hline 2020 & Oliveros .A & 6 & COVID-19 & & Favorable results \\
\hline
\end{tabular}

Table 2: Use of Etanercep in patients and recommendations in respiratory distress syndrome and atypical pneumonia.

Recently, Duret P-M [12] published the case of an immunocompromised patient with the clinical picture of COVID-19, with nonsevere respiratory distress, who was administered subcutaneous Etanercept $50 \mathrm{mg}$, thus preventing admission to the severe intensive care unit.

The study motivation is to describe the clinical evolution of patients identified with non-severe respiratory distress syndrome and with an L profile, and those with the inflammatory factor neu- tralized due to a probable cytokine release syndrome and therefore reduce the percentage of admission to an intensive care unit.

\section{Materials and Methods}

Population and grouping study

The motivation for this study started with the detection of two cases with characteristic virus symptoms (SARS-CoV-2) COVID-19, on May 5 and 7 of this year (2020). We performed this study as 
Use of Immunomodulators (Etanercept) in a Miniseries with Covid-19 Patients, to Decrease the Progress of Complications and Risks of Entry into Critical Care. Bibliography Review

descriptive and prospective, in patients from the Institute of Reproduction and Gynecology of Acapulco (IREGA) located in Acapulco, Mexico. From March 2, 2020 to May 28, 2020, where the recommended sanitary measures and the program for the diagnosis of COVID-19 were implemented in the outpatient clinic, Inclusion Criteria for the virus is described with the following symptoms: fever, cough, headache plus dyspnea, myalgia, arthralgia, odynophagia and gastrointestinal issues. As risk factors, these were included: pregnancy and obesity, all patients with symptoms and injuries on the chest X-ray and computed axial tomography (CT) compatible with pneumonia confirmed as SARS-CoV-2. As for Exclusion Criteria: Febrile syndrome of another etiology, such as Dengue, Zika, Chikungunya or other endemics in the area.

Patients with suspected virus (SARS-CoV-2) COVID-19, were evaluated and the rPCR test was performed in an external laboratory of the clinic. They were asked to follow up at home and others were send to hospitalization unit with indications to report: increased fever, attack on the general state, or the appearance of symptoms of respiratory distress. Two procedures were carried out: domiciliary and hospital with non-invasive ventilatory support.

We were supported by a specialist in Pneumology and another specialist in a Critical Intensive Care Unit. Tests of BH, QS, TP, TPT and platelets were indicated. Liver function tests (PFH) and oximetry evaluation for 5 minutes with the monitor of the institution.

The diagnosis of SARS-CoV-2 infection was confirmed by a positive real-time reverse transcriptase (rPCR) polymerase chain reaction of clinical nasal swabs, analyzed by an external Molecular Virology unit of the unit.

Patients with respiratory distress were evaluated according to $\mathrm{L}$ and $\mathrm{H}$ profiles, based on the guidelines of the European Respiratory Society/American Thoracic of 2017 were followed (Supplement 2).

The intervention was the administration of Enbrel (Pfizer, Immunex, Seattle, WA), Etanercet $50 \mathrm{mg}$ (subcutaneous), which is a human tumor necrosis factor receptor fusion protein(TNFR) produced by DNA recombination technology in the mammalian cellular expression system, originated in a chinese hamster ovary (CHO) $[1,2]$. This a dimer of a chimeric protein genetically developed by the fusion of the extracellular ligand binding domain of human tumor necrosis factor receptor-2 (TNFR2/p75) and the Fc domain of IgG1.
For administration, two groups were aligned: A) Mild: with fever, respiratory tract symptoms and images compatible with pneumonia, gastrointestinal symptoms, risk factors such as pregnancy and obesity. B) Moderate: any of the following signs and symptoms: breathing difficulty, respiratory rate $>30 / \mathrm{min}$. b. (in the resting state), oxygen saturation less than or equal to $93 \%$. c. $\mathrm{PaO}_{2}$ less than or equal to $60 \mathrm{mmHg}$.

Severe stages with respiratory distress requiring invasive ventilatory assistance were not included.

The research was made out of 76 working days and from 526 consultations in: 1) Infertility evaluation and program follow-up, 2) Gynecological Consultation, 3) Obstetric Consultation, 4) Structural Ultrasound, 5) Nutrition Consultation, 6) Psychology Consultation (Figure 3).

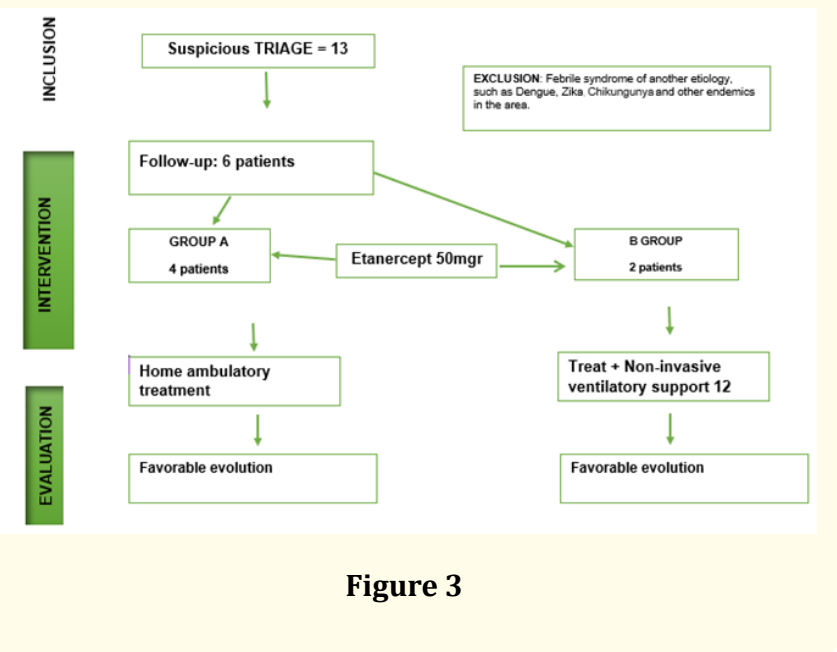

Where 13 were identified with suspected virus infection (SARSCoV-2) COVID-19, only 6 accepted the administration and monitoring of the protocol.

A bibliographic review was performed with electronic search in PubMed, Google Scholar, EMBASE and the Cochrane Library databases for articles published between 2002 and 2020, using a combination of controlled vocabulary and free text in English with the following keywords: Covid-10 and treatment, immune system response, hyperinflammation and repurposing antirheumatic drugs, respiratory syndrome (MERS), Treatment of Severe COVID-19 pa- 
tients, cytokine storm in COVID-19, treatments used in Rheumatology for COVID-, and Etanercept. A manual search of all references was also performed.

Summed up in table 1: the antirheumatic immunological drugs currently tested in clinical trials of patients with COVID-19 and in table 2: The use of Etanercep in patients and recommendations in respiratory distress syndrome and atypical pneumonia.

\section{Outcome}

The primary result of this study is not entering the critical intensive care unit. The second result is remission of symptoms and clinical picture of (SARS-CoV-2) COVID-19.

\section{Patient participation}

Only four out of six patients agreed to comment on their results and openly participate in the study and share their data.

Two of them did not accept, for fear to be discriminated in their communities by the pandemic.

\section{Statistical analysis}

Descriptive analysis of demographic and clinical data of the 6 patients. The measures and average of the clinical analysis available of the result and the associated clinical variables. No other statistical analysis or contingency tables were analysed due to the small number of cases.

\section{Results}

A total of 526 consultations in 76 days, with an average of 6.92 per working day, of which: 1) Infertility Assessment and program follow-up 292 (56\%), 2) Gynecological Consultation 41 (8\%), 3) Obstetric Consultation 43 ( 8\%), 4) Structural ultrasound 52 $(10 \%), 5)$ Nutrition Consultation 42 (8\%), 6) Psychology Consultation 41 (8\%) (Figure 4).

Of 13 identified patients, only 6 patients with positive tests and symptoms of viral infection with (SARS-CoV-2) COVID-19 accepted the administration of the immunomodulator and followed the protocol. From 4 patients with symptoms of fever, cough, headache plus dyspnea, myalgia, arthralgia, odynophagia, only one presented gastrointestinal symptoms and only one patient with obesity. One of our medical staff members had symptoms and it only required hospital care and non-invasive ventilatory support, with nasal tips and oxygen on free demand to maintain oxygen saturation figures between 92 - 96\% at rest. Two patients were able to supply oxygen at home and maintain communication by video calling and WhatsApp texting for adjustments of doses, and received an average visit of 2 times a per day. Two pregnant patients presented mild symptoms: one of 13 weeks, with a live fetus, was evaluated and received paracetamol, hydroxychloroquine and azithromycin scheme. The other patient, with a 32-week pregnancy, received the same medication scheme, and she had no regular follow-up due to her confinement and fear of going out to perform the examinations. Three patients presented injuries on the chest X-ray and computed axial tomography compatible with pneumonia confirmed by SARSCoV-2 with an infiltration between 15 to $60 \%$. It was not possible to perform chest $\mathrm{x}$-rays and computerized axial tomography in the others.

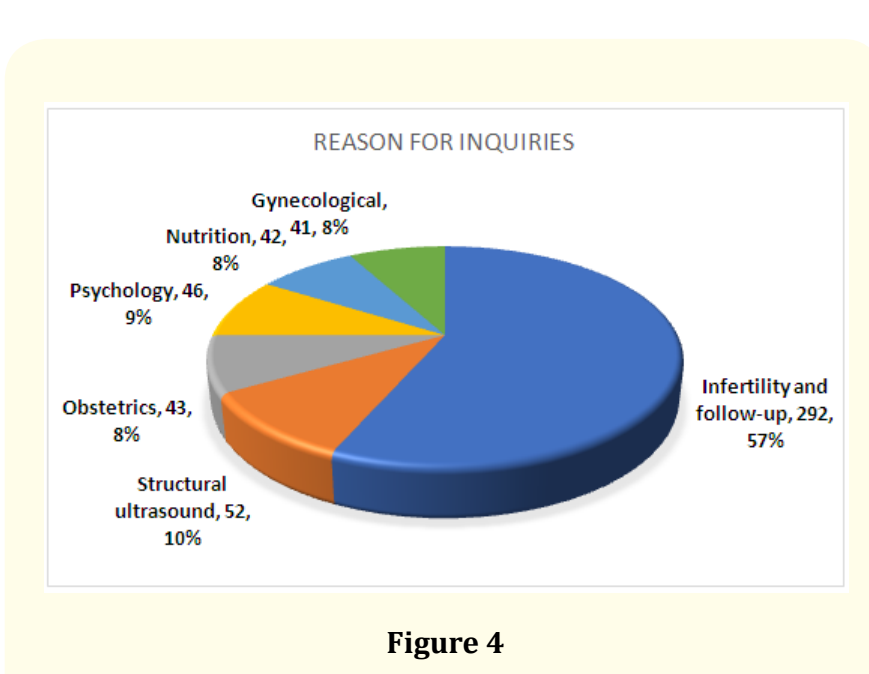

In the laboratory tests, leukopenia was observed in all of them. In addition to that, elevated $\mathrm{C}$ reactive proteins with elevated DHL, oximetry and blood gas registers showed mild to moderate hypoxemia of those who presented symptoms of respiratory distress, and their evolution improved on an average of 8 days after presenting respiratory symptoms, and only one was assessed for early intubation, for showing percentages lower than $84 \%$ of saturation on 4 occasions.

Hypoalbuminemia was present in all of them, and the other parameters did not show constant changes.

No patient required invasive ventilatory assistance and did not require admission to the intensive care unit. 
Use of Immunomodulators (Etanercept) in a Miniseries with Covid-19 Patients, to Decrease the Progress of Complications and Risks of Entry into Critical Care. Bibliography Review

14

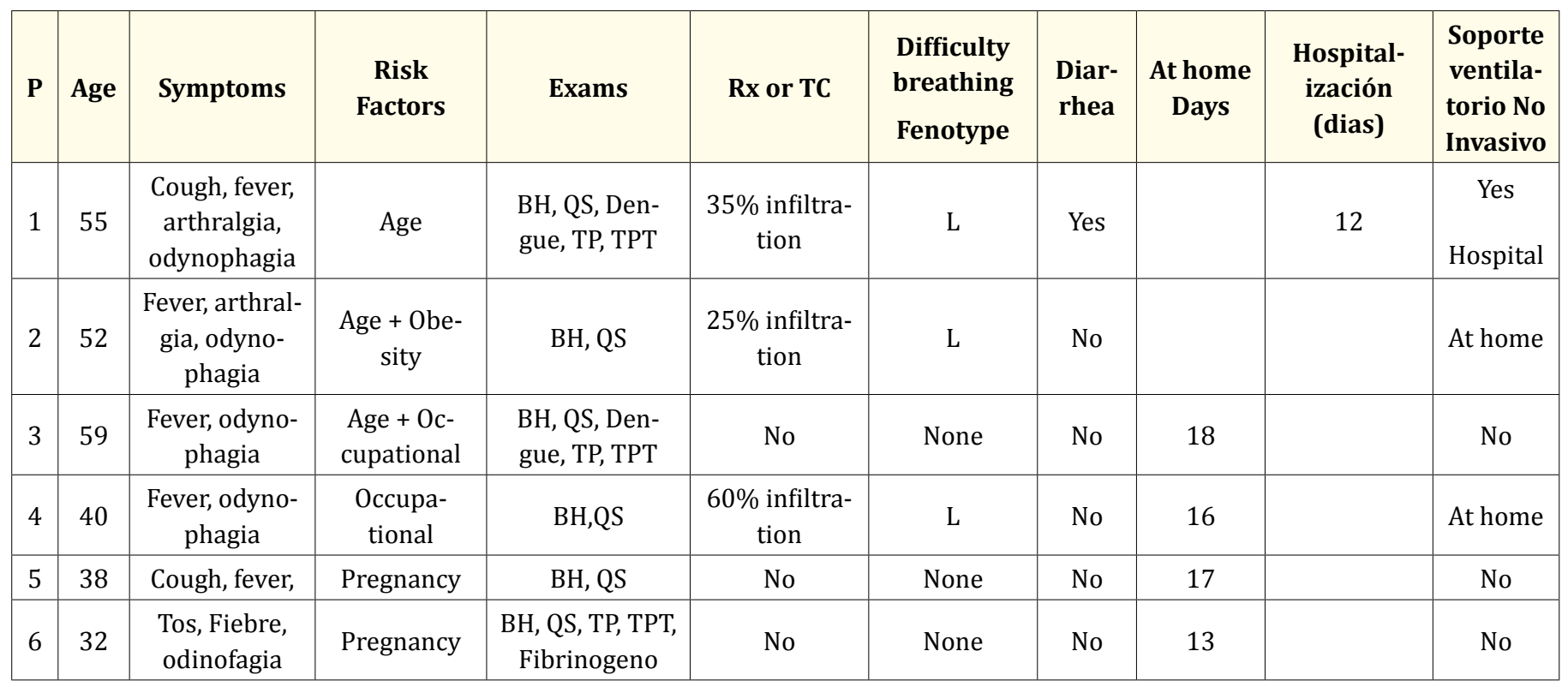

Table 3: Demographic and clinical characteristics of patients.

P: Patient Number; RX: Radiography Plate; CT: Computed Axial Tomography; At home number of days in evolution.

\begin{tabular}{|c|c|c|c|c|c|c|c|c|c|c|}
\hline $\mathbf{P}$ & $\begin{array}{l}\mathrm{Hb} / \\
\text { Hto }\end{array}$ & $\begin{array}{c}\text { Leukocytes } \\
10^{3} / \mathrm{mm}^{3} \\
\text { Entry/exit }\end{array}$ & $\begin{array}{l}\text { C Reactive } \\
\text { Protein }\end{array}$ & $\begin{array}{c}\text { QS mg/ } \\
\text { dl }\end{array}$ & $\begin{array}{l}\text { DHL } \\
\text { UI/L }\end{array}$ & $\begin{array}{l}\text { ALBUMIN } \\
\text { g/DL }\end{array}$ & TP/TPT & $\begin{array}{c}\text { Fibrinogen } \\
\text { Mg/DL }\end{array}$ & $\begin{array}{c}\text { Oximetry Average } \\
\text { Repose sin/5L }\end{array}$ & $\begin{array}{l}\text { Gasometry } \\
\mathrm{PCO}_{2} / \mathrm{HCO}_{3}\end{array}$ \\
\hline 1 & 10.2 & $4.6 / 7.5$ & 31.3 & 94.2 & 442.2 & 2.8 & $14 / 42$ & 401 & $88 \% / 92 \%$ & $30.5 / 26.6$ \\
\hline 2 & 10.62 & $4.8 / 8.3$ & 15.5 & 111.8 & 334.8 & 3.1 & $12 / 48$ & 452 & $86 \% / 94 \%$ & $34.3 / 24.3$ \\
\hline 3 & 9.5 & $4.8 / 8.8$ & 10.5 & 88.1 & 229.2 & 4.2 & $15 / 38$ & 344 & $86 \% / 94 \%$ & $28.2 / 28.7$ \\
\hline 4 & 11.1 & $5.8 / 7.2$ & 36.6 & 101.2 & 345.8 & 4.4 & $13 / 41$ & 412 & $86 \% / 96 \%$ & $31.0 / 27.3$ \\
\hline 5 & 10.25 & $6.9 / ?$ & 22.3 & 112.2 & -- & 2.7 & $13 / 38$ & -- & $88 \% / 92$ & -- \\
\hline 6 & 10.7 & $7.4 / ?$ & 11.5 & 87.9 & -- & -- & -- & -- & -- & -- \\
\hline
\end{tabular}

Table 3: Laboratory medians measures.

P: Patient Number; QS: Blood Chemistry Test; DHL; LDH: Lactate Dehydrogenase TP/TPT Coagulation.

\section{Discussion}

This study describes the clinical course of six patients, where four of them had contact or interaction with the clinic, where assisted reproduction techniques are developed, and we had the ability to detect them and send them for appropriate care. It is shown that the clinics are not exempt from having the risk, due to the asymptomatic feature of the carrier, and it can be said that it's the perfect accomplice in the spread of this pandemic.
Kalil 's analysis [3] says that the world is now facing a pandemic of SARS-CoV-2 (coronavirus 2 of severe acute respiratory syndrome), for which no proven specific therapies are available, other than supportive care. In China, Italy, France, Spain, and also in Latin America (where you find the highest peaks of contagion and high mortality rates), a large number of patients have received therapies for compassionate use, that are only palliative, and not proven in their efficacy, such as chloroquine, hydroxychloroquine, azithromycin, lopinavir-ritonavir, favipiravir, remdesivir, ribavirin, 
Use of Immunomodulators (Etanercept) in a Miniseries with Covid-19 Patients, to Decrease the Progress of Complications and Risks of Entry into Critical Care. Bibliography Review

interferon, convalescent plasma, steroids and anti-IL-6 inhibitors, based on their in vitro antiviral or anti-inflammatory properties. These therapies have been administered mainly without controls, except for some randomized trials that started in China and more recently in the USA.

In Mexico, the Ministry of Health and the Mexican Institute of Social Security on May 5, 2020, presents a combination of antibiotics, antivirals, anticoagulants and immunomodulators in the different stages of the disease.

There is a great challenge to find the vaccine or the specific antiviral agent against this virus. One proposal is to change the course of the disease that leads to severe respiratory distress syndrome and death.

The stage of self-induced lung injury due to aberrant release of cytokines or cytokine storm [4,5], already described in other Coronavirus infections such as the Severe Acute Respiratory Syndrome(SARS), the Middle East Respiratory Syndrome(MERS) and the Coronavirus Disease 2019 (COVID-19) should be considered as the main cause of aggravation and mortality, due to the liberation of phenomena such as hematophagogocytic lymphocytosis with damage to the lung tissue and lesions to other organs.

In a most recent review, it visualizes the use of various immunomodulatory therapies, including interleukin (IL) -6 antagonists, granulocyte colony stimulating factor (GM-CSF) inhibitor, IL-1 antagonists, IL-17 antagonists, and agents of antitumor necrosis factor (TNF) for this cytokine storm, to solve and limit further inflammation and tissue damage and therefore, change the course of the disease.

In this study, we describe the preliminary data from our experience with the administration of Etanercept on two hospitalized patients, and also on another patient with oxygen support at home, and on three outpatients in a region of the state of Guerrero, Mexico, that were detected within an Assisted Reproduction Techniques Selection Program.

Our study shows the weakness of having a small number of detected individuals, so no correlation can be made, and not all the patients could be followed up with the tests, due to the contingency difficulties in terms of patient mobility, as well as the availability and financial resources of the patients.
The study shows its strength by demonstrating the recovery of the symptoms of fever and respiratory distress within 12 to 18 hours, and only one hospitalized patient needed early intubation because of his oximeter figures of $82 \%$ for $3 \mathrm{hrs}$. However, it turned out to be not necessary. This improved with the pronation position, but none of the patients did evolve into severity, preventing admission to the severe intensive care unit and thereby reducing the invasive process of intubation for ventilatory support.

The two patients with a pregnancy of 13 and 32 weeks, only reported fever for $48 \mathrm{hrs}$, and only one of them reported respiratory distress at the beginning with favorable recovery at $18 \mathrm{hrs}$ after the administration of Etanercept. Their pregnancies are ongoing, and it cannot be demonstrated if the evolution was from the group that would or would not evolve into the respiratory complication.

The administration of Hydrochloroquine that accompanied the treatment of every patients cannot have any positive attribution, and two recent publications $[13,14]$ haven't demonstrated any beneficial effect, and only adverse secondary risks.

The use of Etanercept in this group of patients was considered due to availability, although it has a cost disadvantage. The first series published by Yanik [14] about the treatment of idiopathic pneumonia syndrome mentions that, after allogeneic hematopoietic stem cell transplantation, the morbidity and mortality of 15 patients were considerably reduced, and satisfactory evolution and non-admission to the critical intensive care room was observed. We were encouraged by these series and the Duret PM report [9] on the first case of COVID-19.

The threshold between moderate and severe disease to decide an intervention with the application of the immunomodulator represents a challenge for the physician, which in our study has demonstrated that the administration in early stages with the appearance of fever and cough have more encouraging results. Studies made by Yueying [15] where frosted glass nodules, patchy or pinpoint frosted glass opacities, patch consolidation, fibrous streaks, irregular solid nodules, and artificial intelligence shows between $7 \%$ and $10 \%$ of mild to moderate stage of the disease, where early use should be considered.

Marta C [16] recently reported the use of Tocilizumab in 21 seriously ill patients, with no improvement and with patients being admitted to intensive care units. Another report by author Klopfen- 
Use of Immunomodulators (Etanercept) in a Miniseries with Covid-19 Patients, to Decrease the Progress of Complications and Risks of Entry into Critical Care. Bibliography Review

steina [17], in a series of 20 cases with the same immunomodulators reports, has a statistically significant difference in decreasing admission to the serious intensive care unit and death in favor of Tocilizumab.

Different immune therapies will continue to be published as long as the vaccine and the definitive solution to stop the virus is yet to be found. The use of anti-inflammatory drugs and corticosteroids in the early stages of the disease should also be considered, since it has been shown that there is more benefit than the risks of a disease that continues its course towards severity.

The challenge for the centers of Assisted Reproduction Techniques is to create the concept of "new normal" where the staff could be affected as it happened to one of the members of the clinic (Supplement 3) and there is a need to implement new protocols without compromising reproductive results, but above all, with the aim of safeguarding everyone's health.

\section{Conclusion}

The administration of the Etanercept immunomodulator in patients with (SARS-CoV-2) in the mild to moderate stage, has great potential in changing the course of the disease and reducing the risk of admission to the intensive care unit. The potential risk of invasive ventilatory assistance was not present in this miniseries. The follow-up has many weaknesses, and more structured studies are required, due to the fact that this group was in no favorable conditions due to the pandemic.

More patients and more controlled and randomized studies are necessary to reinforce our hypothesis.

\section{Supplement}

Supplement 1

Name:

Date:

\begin{tabular}{|l|c|c|}
\hline Variantes & Stability values & Results \\
\hline Heart rate & $<100 \mathrm{lpm}$ & \\
\hline Breathing frequency & $<24 \mathrm{RPM}$ & \\
\hline Axillary saturation & $<36.2$ & \\
\hline Systolic blood pressure & $>90 \mathrm{mmHg}$ & \\
\hline Oxygen saturation & $>90 \%$ & \\
\hline Level of consciousness & Adequate & \\
\hline
\end{tabular}

\section{Supplement 2}

Phenotypes

COVID-19 pneumonia, Type L

At the beginning, COVID-19 pneumonia presents with the following characteristics:

- Low elastance: the nearly normal compliance indicates that the amount of gas in the lung is nearly normal [3].

- Low ventilation to perfusion (VA/Q) ratio: since the gas volume is nearly normal, hypoxemia may be best explained by the loss of regulation of perfusion and by loss of hypoxic vasoconstriction. Accordingly, at this stage, the pulmonary artery pressure, should be near normal.

- $\quad$ Low lung weight: Only ground-glass densities are present on CT scan, primarily located subpleurally and along the lung fissures. Consequently, lung weight is only moderately increased.

- Low lung recruitability: the amount of non-aerated tissue is very low, consequently the recruitability is low [4].

\section{The Type $\mathrm{H}$ patient}

- High elastance: The decrease of gas volume due to increased edema accounts for the increased lung elastance.

- High right-to-left shunt: This is due to the fraction of cardiac output perfusing the non-aerated tissue which develops in the dependent lung regions due to the increased edema and superimposed pressure.

- High lung weight: Quantitative analysis of the CT scan shows a remarkable increase in lung weight (>1.5 kg), on the order of magnitude of severe ARDS [11].

- $\quad$ High lung recruitability: The increased amount of non-aerated tissue is associated, as in severe ARDS, with increased recruitability [12].

Gattinoni L., et al. COVID-19 pneumonia: different respiratory treatment for different phenotypes? (2020) Intensive Care Medicine; DOI: 10.1007/s00134-020-06033-2.

Supplement 3

(Figure) 


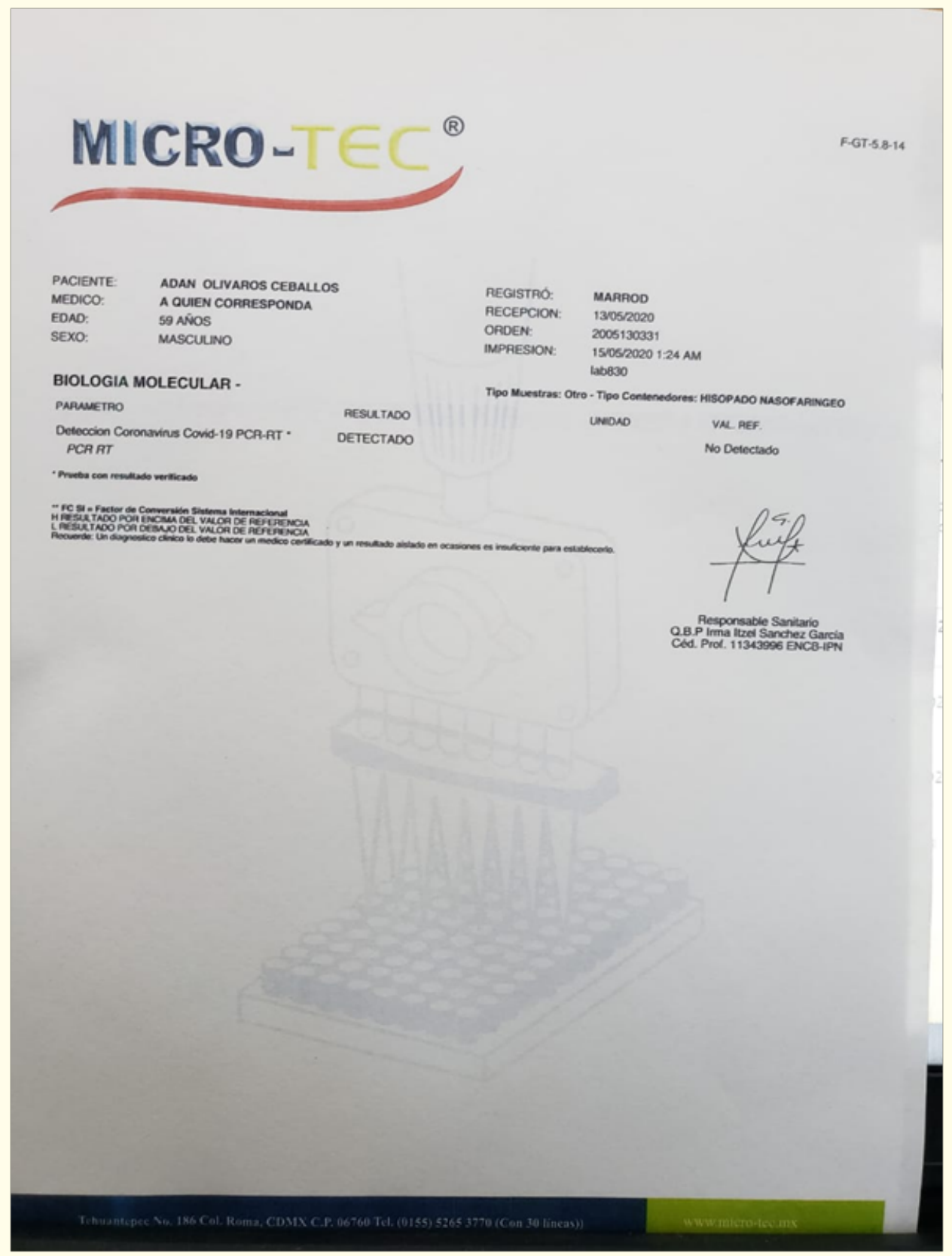

Figure

\section{Bibliography}

1. Zhu N., et al. "A Novel Coronavirus from Patients with Pneumonia in China, 2019". The New England Journal of Medicine (2020).
2. Zhou P., et al. "A pneumonia outbreak associated with a new coronavirus of probable bat origin". Nature 579 (2020): 270.

3. Kalil A., et al. "Treating COVID-19-Off-Label Drug Use, Compassionate Use, and Randomized Clinical Trials During Pandemics". JAMA (2020).

Citation: Adán Oliveros-Ceballos., et al. "Use of Immunomodulators (Etanercept) in a Miniseries with Covid-19 Patients, to Decrease the Progress of Complications and Risks of Entry into Critical Care. Bibliography Review”. Acta Scientific Women's Health 2.8 (2020): 08-18. 
4. Jennifer R., et al. "Into the Eye of the Cytokine Storm". Microbiology and Molecular Biology Reviews (2012).

5. Adurrahman T., et al. "COVID-19, immune system response, hyperinflammation and repurposing antirheumatic drugs". Turkish Journal of Medical Sciences 50 (2020): 620-632.

6. Yuen KY., et al. "Human infection by avian influenza A H5N1". Hong Kong Medical Journal 11 (2005): 189-199.

7. Ennio G., et al. "COVID-19 infection and rheumatoid arthritis: Faraway, so close!”. Autoimmunity Reviews 19 (2020) 102523.

8. Picchianti D., et al. "Review Cytokine Release Syndrome in COVID-19 Patients, A New Scenario for an Old Concern: The Fragile Balance between Infection". International Journal of Molecular Sciences 21.9 (2020): 3330.

9. Ben Goffe., et al. "Etanerceptt: an overvie". Journal of the Academy American of Dermatology 49 (2003).

10. Hussell T., et al. "Openshaw Inhibition of tumor necrosis factor reduces the severity of virus-specific lung immunopathology". European Journal of Immunology 31 (2001): 2566-2573.

11. Yanik G., et al. "Etanercept (Enbrel) Administration for Idiopathic Pneumonia Syndrome after Allogeneic Hematopoietic Stem Cell Transplantation". Biology of Blood and Marrow Transplantation 8 (2002): 395-400.

12. Duret PM., et al. "Recovery from COVID-19 in a patient with spondyloarthritis treated with TNF-alpha inhibitor etanercept". Annals of the Rheumatic Diseases (2020).

13. Mandeep R., et al. "Hydroxychloroquine or chloroquine with or without a macrolide for treatment of COVID-19: a multinational registry análisis". Lancet (2020).

14. Gbinigie., et al. "Should chloroquine and hydroxychloroquine be used to treat COVID-19? A rapid review". BJGP Open (2020).

15. Yueying., et al. "Initial CT findings and temporal changes in patients with the novel coronavirus pneumonia (2019-nCoV): a study of 63 patients in Wuhan". European Radiology 30.6 (2020): 3306-3309.

16. Marta C., et al. "Tocilizumab for Treatment of Severe COVID-19 Patients: Preliminary Results from SMAtteo COvid19 REgistry (SMACORE)". Microorganisms 8 (2020): 695.

17. Zayeta K., et al. "Tocilizumab therapy reduced intensive care unit admissions and/or mortality in COVID-19 patients". Médecine et Maladies Infectieuses (2020).
18. Gasparyan., et al. "Perspectives of Immune Therapy in Coronavirus Disease 2019". Journal of Korean Medical Science 35.18 (2020): e176.

19. Joan M., et al. "A comparation of etnercept and methotrexate in patients with early rheumatoid arthritis". New England Journal of Medicine (2000).

\section{Assets from publication with us}

- Prompt Acknowledgement after receiving the article

- Thorough Double blinded peer review

- Rapid Publication

- Issue of Publication Certificate

- High visibility of your Published work

Website: www.actascientific.com/

Submit Article: www.actascientific.com/submission.php

Email us: editor@actascientific.com

Contact us: +919182824667 